\title{
Do the Magic Angle Effects or Susceptibility Effects Affect the Visualization of Nigrosome 1?
}

I read with great interest the recently published article by Arai et $\mathrm{al}^{1}$ in the American Journal of Neuroradiology. In this article, the authors claimed that the asymmetric visualization of nigrosome 1 is affected by the magic angle and susceptibility. They also suggested that these challenges in visualization are caused by the anatomic slant structure of nigrosome 1. For proper assessment of nigrosome 1 on MR imaging, it is of the utmost importance that researchers should be familiar with its anatomy and obtain high-spatial-resolution imaging to reduce partial-volume effects. In this regard, I am concerned about the methods used by the authors of this article.

First, the authors claimed that the MR imaging visualization of nigrosome 1 is often poor because of the asymmetry of this cell cluster, regardless of whether nigrosome 1 is healthy. I tried to find any relevant studies with regard to the cell cluster asymmetry in nigrosome 1 but to no avail. It, therefore, would be better to add any reference to this description.

Second, it has been reported that the CNS does not show magic angle effects ( $\mathrm{T} 2$ prolongation at certain angles) because it has no ordered collagen. ${ }^{2}$ It, therefore, is implausible to describe that visualization of nigrosome 1 is affected by magic angle effects. Because a multiecho gradient recalled-echo sequence was used in this study, there may be changes of $\mathrm{T}^{\star}{ }^{\star}$ contrast in certain regions of the white matter. It has been shown that the relative orientation of white matter fibers to the $B_{0}$ field significantly affects $\mathrm{T} 2{ }^{*}$ measurements, and the dominant source of this orientation dependency is susceptibility effects from myelin. ${ }^{3}$ Myelin, however, is not, or is scarcely, present in nigrosome $1 .{ }^{4}$ Thus, neither magic angle effects nor susceptibility effects may affect the image contrast in healthy nigrosome 1 .

Third, even if nigrosome 1 visualization is affected by the magic angle effects due to its slant, nigrosome 1 should have higher signal intensity in nontilted head imaging than in tilted head imaging. The opposite results, however, were presented in this study.

Fourth, the authors indicated nigrosome 1 on the susceptibility map in Fig 5. The indicated structures with hypointensity are connected to the slightly hypointense regions below the substantia nigra. Nigrosome 1, however, is located between the 2 hyperintense areas on quantitative susceptibility mapping because it is seen as a hyperintense region between the 2 hypointense regions on SWI (also known as the "swallow tail sign"). Nigrosome 1 is also located more anteriorly than that in Fig 5. ${ }^{1}$ The structure indicated by the authors, rather, would be the medial lemniscus (based on the Duvernoy's Atlas of the Human Brain Stem and Cerebellum), ${ }^{5}$ not nigrosome 1 , which is supported by the fact that it shows orientation-dependent signal changes because of its myelin content. It would have been better to test if higher-spatial resolution imaging $\left(\mathrm{eg}, 0.5 \times 0.5 \times 1.0 \mathrm{~mm}^{3}\right)$ shows similar results because nigrosome 1 is very small and easily affected by a partial-volume effect. ${ }^{6}$

\section{REFERENCES}

1. Arai N, Kan H, Ogawa M, et al. Visualization of nigrosome $\mathbf{1}$ from the viewpoint of anatomic structure. AJNR Am J Neuroradiol 2020; 41:86-91 CrossRef Medline

2. Bydder M, Rahal A, Fullerton GD, et al. The magic angle effect: a source of artifact, determinant of image contrast, and technique for imaging. J Magn Reson Imaging 2007;25:290-300 CrossRef Medline

3. Oh SH, Kim YB, Cho ZH, et al. Origin of $\mathbf{B 0}$ orientation dependent $\mathbf{R 2}\left(^{(}\right)\left(=\mathbf{1} / \mathbf{T} 2\left(^{*}\right)\right)$ in white matter. Neuroimage 2013;73:71-79 CrossRef Medline

4. Massey LA, Miranda MA, Al-Helli O, et al. 9.4T MR microscopy of the substantia nigra with pathological validation in controls and disease. Neuroimage Clin 2017;13:154-63 CrossRef

5. Naidich TP, Duvernoy HM, Delman BN, et al. Duvernoy's Atlass of the Human Brain Stem and Cerebellum. Austria: Springer-Verlag/Wien; 2009

6. Kim EY, Sung YH, Lee J. Nigrosome 1 imaging: technical considerations and clinical applications. Br J Radiol 2019;92:20180842 CrossRef Medline 